Article

\title{
Controlled Synthesis of Hydroxyapatite Nanomaterials Regulated by Different Phosphorus Sources
}

\author{
Mei-li Qi ${ }^{1,2, *(\mathbb{D},}$, Sijia Qin ${ }^{1}$, Yin-chuan Wang ${ }^{2}$, Shengkun Yao ${ }^{3,4}{ }^{\mathbb{C}}$, Liang $\mathrm{Qi}^{5}$, Yanling Wu ${ }^{1}$, \\ Yu-peng $\mathrm{Lu}^{2}$ and Fengkun Cui ${ }^{1, *}$ \\ 1 School of Transportation and Civil Engineering, Shandong Jiaotong University, Ji'nan 250357, China; \\ 201921801055@stu.hebut.edu.cn (S.Q.); 204145@sdjtu.edu.cn (Y.W.) \\ 2 School of Materials Science and Engineering, Shandong University, Ji'nan 250061, China; \\ bio_ycwang@yeah.net (Y.-c.W.); biosdu@sdu.edu.cn (Y.-p.L.) \\ 3 Shandong Provincial Engineering and Technical Center of Light Manipulations \& Shandong Provincial Key \\ Laboratory of Optics and Photonic Device, School of Physics and Electronics, Shandong Normal University, \\ Ji'nan 250358, China; yaoshk@sdnu.edu.cn \\ 4 Collaborative Innovation Center of Light Manipulations and Applications, Shandong Normal University, \\ Ji'nan 250358, China \\ 5 Shandong Chaoyue Data Control Electronics Co., LTD, Ji'nan 250100, China; qiliang@chaoyue.com.cn \\ * Correspondence: beauty0507@163.com (M.-1.Q.); 204118@sdjtu.edu.cn (F.C.)
}

Received: 22 July 2020; Accepted: 3 August 2020; Published: 6 August 2020

\begin{abstract}
The morphology, nanostructures, and crystallinity of hydroxyapatite (HA) materials have significant effects on their physicochemical properties and biomedical applications. However, the controllable synthesis of HA nanomaterials with various size and morphology using the same synthesis system, though desirable, has remained a challenge. In this work, we successfully synthesized HA nanomaterials with different morphologies via a one-step solvothermal route in the same reaction system. By using $\left(\mathrm{NaPO}_{3}\right)_{3}, \mathrm{Na}_{3} \mathrm{PO}_{4} \cdot 12 \mathrm{H}_{2} \mathrm{O}$ and $\mathrm{NaH}_{2} \mathrm{PO}_{4} \cdot 2 \mathrm{H}_{2} \mathrm{O}$ as phosphorus sources, the growth of $\mathrm{HA}$ crystals was regulated, resulting in the transformation of $\mathrm{HA}$ nanomaterials morphology from nanorods to nanowires. Different concentrations of $\mathrm{PO}_{4}{ }^{3-}$ and $\mathrm{OH}^{-}$ions in the reaction environments regulated by different phosphates lead to different nanostructures of HA crystals. Our work provides an instructive way to controllably fabricate HA nanomaterials with various morphologies and will widen the biomedical applications of HA materials.
\end{abstract}

Keywords: hydroxyapatite; nanomaterials; controllable synthesis; phosphorus sources

\section{Introduction}

Hydroxyapatite $\left(\mathrm{HA}, \mathrm{Ca}_{10}(\mathrm{OH})_{2}\left(\mathrm{PO}_{4}\right)_{6}\right)$ has similar chemical composition with natural bone and teeth [1,2], showing excellent biological properties. The crystal structure of hydroxyapatite (HA) belongs to six fold space group $\left(\mathrm{P}_{3} / \mathrm{m}\right.$, the highest symmetry) with unit-cell parameters of $\mathrm{a}=\mathrm{b}=9.421 \mathrm{~nm}$ and $\mathrm{c}=6.884 \mathrm{~nm}$ [3]. HA has been widely used in biomedical fields such as hard tissue engineering, drug release, protein adsorption and bone cement filler [4-7]. Among various HA materials, nanophase HA is preferred because it can orchestrate cellular behavior by providing specific morphological and biological cues [8-11]. For example, ultralong HA nanowires with a high aspect ratio are very promising for adsorbent of organic pollutants, non-flammable paper, bone and tooth repair and bio-imaging [12-15].

Until now, the facile and controllable synthesis of HA nanomaterials with well-defined structure, size and morphology under the same synthesis system is desirable but remains highly challengeable. 
Many synthetic methods have been employed to obtain HA nanowires, such as hydrothermal method [16,17], reverse micelles approach [18], hard template technique [19], micro-wave-assisted process [20] and sol-gel synthesis [21]. Phosphorus source is an important factor influencing the morphology of HA nanomaterials [22]. Recently, ultralong HA nanowires were solvothermally synthesized by using a series of phosphate sodium salts [23]. However, the synthesis time is relatively long and corresponding formation mechanism of HA nanowires needs further study.

In this study, we report a facile solvothermal method to synthesize aggregated HA nanorods, HA nanowires accompanied with flowerlike HA aggregates and ultralong HA nanowires under the same synthetic system by using three different types of phosphate sources. Effects of various phosphorus sources on the morphologies of HA nanomaterials are investigated and the morphological transition mechanism is proposed. This study provides an instructive way to realize the morphological transformation of HA nanomaterials without changing the synthetic system.

\section{Materials and Methods}

Anhydrous calcium chloride $\left(\mathrm{CaCl}_{2}, \mathrm{AR}\right)$, sodium hydroxide $(\mathrm{NaOH}, \mathrm{AR})$, sodium trimetaphosphate $\left[\left(\mathrm{NaPO}_{3}\right)_{3}, \mathrm{AR}\right]$, trisodium phosphate dodecahydrate $\left(\mathrm{Na}_{3} \mathrm{PO}_{4} \cdot 12 \mathrm{H}_{2} \mathrm{O}, \mathrm{AR}\right)$, sodium dihydrogen phosphate $\left(\mathrm{NaH}_{2} \mathrm{PO}_{4} \cdot 2 \mathrm{H}_{2} \mathrm{O}, \mathrm{AR}\right)$, oleic acid and ethanol were purchased from Sinopharm Chemical Reagent Corporation (Shanghai, China). All chemical reagents for the synthesis process were used as received.

HA nanomaterials with different morphologies were prepared via a solvothermal synthesis. In the experiment, oleic acid ( $6.000 \mathrm{~g})$ and anhydrous ethanol $(6.000 \mathrm{~g})$ were mixed on a magnetic stirrer (Zhengzhou, Henan, China) (300 r/min, $3 \mathrm{~min})$. A total of $10 \mathrm{ml}$ aqueous solutions of $\mathrm{CaCl}_{2}(0.110 \mathrm{~g})$ and $10 \mathrm{ml}$ aqueous solutions of $\mathrm{NaOH}(0.500 \mathrm{~g})$ were added to the above solution, respectively. After mixing well, the aqueous solution $(5 \mathrm{ml})$ of phosphorus source $\left(\left(\mathrm{NaPO}_{3}\right)_{3}: 0.375 \mathrm{~g}\right.$; $\left.\mathrm{NaH}_{2} \mathrm{PO}_{4} \cdot 2 \mathrm{H}_{2} \mathrm{O}: 0.182 \mathrm{~g} ; \mathrm{Na}_{3} \mathrm{PO}_{4} \cdot 12 \mathrm{H}_{2} \mathrm{O}: 0.443 \mathrm{~g}\right)$ was added dropwise into the above mixture, respectively. Then, the reactants were transferred into $50 \mathrm{ml}$ stainless steel autoclaves and heated at 180 ${ }^{\circ} \mathrm{C}$ for $5 \mathrm{~h}$. After being cooled down to room temperature, the resultants were collected and centrifugal cleaned thoroughly at $3000 \mathrm{rpm}$ for $3 \mathrm{~min}$ with deionized water and anhydrous ethanol, and finally dried at $80^{\circ} \mathrm{C}$ in an oven.

The phase composition of the products was measured by a Bruker D8 Advance X-ray diffractometer (XRD, Bruker Optik GmbH, Ettlingen, Germany) with a CuK $\alpha$ radiation source $(\lambda=1.5418 \AA$ ). The functional groups of the products were tested by a Fourier transform infrared spectrometer (FTIR, Bruker Tensor 27, Bruker Optik GmbH, Ettlingen, Germany). The morphology of the products was characterized by the field emission scanning electron microscope (FE-SEM, JSM-7610F, Tokyo, Honshu, Japan). To increase the conductivity of the samples, the products were sputter-coated with platinum before FE-SEM analysis.

\section{Results and Discussion}

\subsection{Phase Analysis}

XRD patterns of the as-synthesized products prepared by three different phosphorus sources, i.e., $\left(\mathrm{NaPO}_{3}\right)_{3}, \mathrm{NaH}_{2} \mathrm{PO}_{4} \cdot 2 \mathrm{H}_{2} \mathrm{O}$ and $\mathrm{Na}_{3} \mathrm{PO}_{4} \cdot 12 \mathrm{H}_{2} \mathrm{O}$ and the bar chart of standard $\mathrm{HA}$ (JCPDS No. 09-0432) are presented in Figure 1. The products show similar XRD patterns and all the main peaks are indexed to HA. The shift of the strongest peak from (211) to (300) is found when $\mathrm{Na}_{3} \mathrm{PO}_{4} \cdot 12 \mathrm{H}_{2} \mathrm{O}$ is used as the phosphorus source, suggesting preferential orientation growth direction along the c-axis of HA [24]. It is concluded that single-phase HA samples can be solvothermally synthesized by using $\mathrm{CaCl}_{2}$ as the calcium source and different phosphates as the phosphorus source in mixed organic solvents of oleic acid and ethanol. The method is applicable for synthesizing HA materials using different kinds of phosphorus sources. 


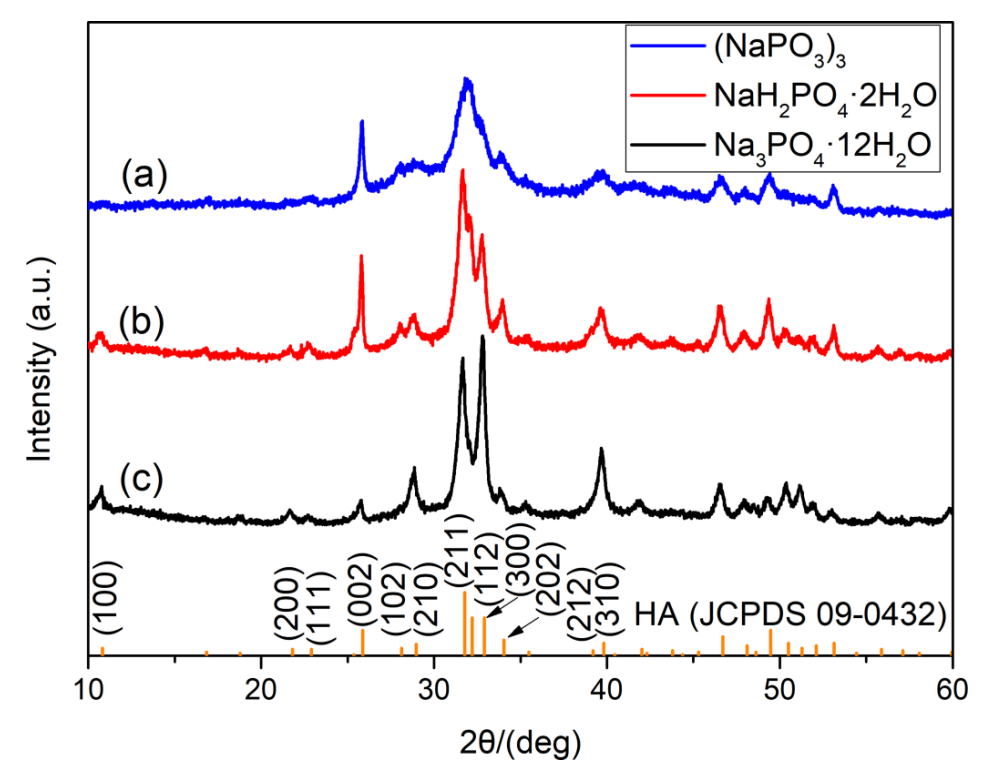

Figure 1. XRD patterns of the as-synthesized products prepared by different phosphorus sources. (a) $\left(\mathrm{NaPO}_{3}\right)_{3}$, (b) $\mathrm{NaH}_{2} \mathrm{PO}_{4} \cdot 2 \mathrm{H}_{2} \mathrm{O}$ and (c) $\mathrm{Na}_{3} \mathrm{PO}_{4} \cdot 12 \mathrm{H}_{2} \mathrm{O}$.

\subsection{Functional Group Analysis}

The FTIR tests were performed to characterize the functional groups of the samples. Figure $2 \mathrm{a}-\mathrm{c}$ represents the FTIR spectra of the as-synthesized samples by using $\left(\mathrm{NaPO}_{3}\right)_{3}, \mathrm{NaH}_{2} \mathrm{PO}_{4} \cdot 2 \mathrm{H}_{2} \mathrm{O}$ and $\mathrm{Na}_{3} \mathrm{PO}_{4} \cdot 12 \mathrm{H}_{2} \mathrm{O}$ as the phosphorous source, respectively. As is shown in Figure 2, all the samples have similar patterns. The broad absorption peak at around $3420 \mathrm{~cm}^{-1}$ belongs to the adsorbed water in all the samples. The absorption peaks at around 1101, 1026, 962, 603, 560 and $472 \mathrm{~cm}^{-1}$ are the characteristic bands for $\mathrm{PO}_{4}{ }^{3-}$ group, and the peaks around 3571 and $633 \mathrm{~cm}^{-1}$ are attributed to the stretching and flexural modes of $\mathrm{OH}^{-}$, further confirming the formation of HA phase [25-27]. Moreover, the peaks at 3010, 2957, 2924, 2853, 1640, 1560, 1460 and $1413 \mathrm{~cm}^{-1}$ corresponding to the oleate group are originated from oleic acid molecules adsorbed on the surface of HA products [23].

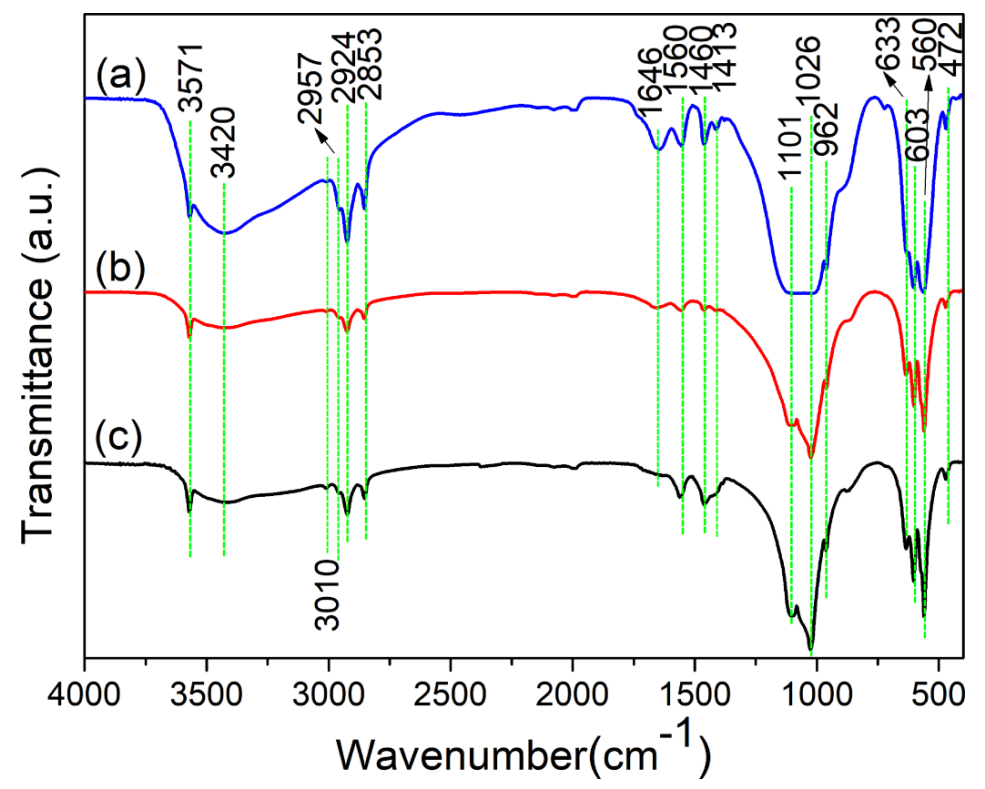

Figure 2. FTIR spectra of the as-synthesized products prepared by different phosphorus sources. (a) $\left(\mathrm{NaPO}_{3}\right)_{3}$, (b) $\mathrm{NaH}_{2} \mathrm{PO}_{4} \cdot 2 \mathrm{H}_{2} \mathrm{O}$ and (c) $\mathrm{Na}_{3} \mathrm{PO}_{4} \cdot 12 \mathrm{H}_{2} \mathrm{O}$. 


\subsection{Microstructural Characterization}

FE-SEM images of the HA products prepared by different kinds of phosphorus sources were investigated. Figure 3 shows the morphology of the sample obtained by using $\left(\mathrm{NaPO}_{3}\right)_{3}$ as a phosphorus source at different magnifications. It can be seen that the products are made up by a thick layer. From the magnified FE-SEM images (Figure 3c), the aggregates are self-assembled by nanorods. Figure 4 demonstrates the FE-SEM images of the sample synthesized by using $\mathrm{NaH}_{2} \mathrm{PO}_{4} \cdot 2 \mathrm{H}_{2} \mathrm{O}$ as a phosphorus source. The dominant morphology of the products is nanowires with ultralong lengths. Except for nanowires, some flowerlike aggregates appear. The magnified FE-SEM image (Figure $4 \mathrm{~d}$ ) indicates that the flowerlike aggregates are self-assembled by nanorods. Figure 5 shows the morphology of the sample obtained by using $\mathrm{Na}_{3} \mathrm{PO}_{4} \cdot 12 \mathrm{H}_{2} \mathrm{O}$ as a phosphorus source. It is clear that the products consist of uniform nanowires. Besides, ultralong HA nanowires can interweave with each other and form a porous structure. From the FE-SEM images with low magnifications (Figure 5a,b), the HA nanowires are ultralong (lengths > several hundred micrometers) with, relatively, a high aspect ratio. These morphology changes among different samples when using different phosphorus sources are consistent with the XRD results.
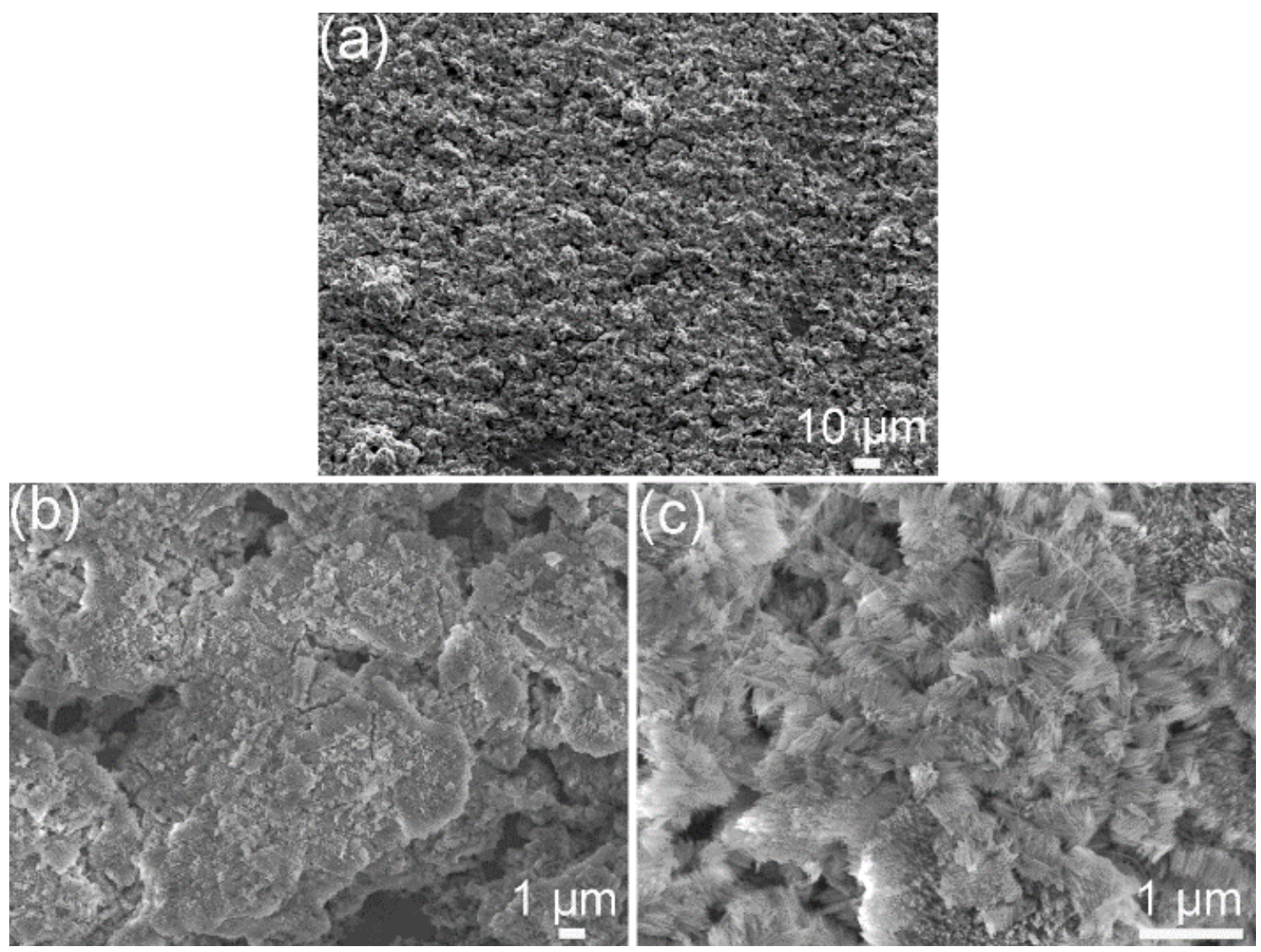

Figure 3. FE-SEM images of hydroxyapatite (HA) products synthesized by using $\left(\mathrm{NaPO}_{3}\right)_{3}$ as the phosphate source at different magnifications. (a) $\times 500,(\mathbf{b}) \times 5000$ and $(\mathbf{c}) \times 20,000$. 

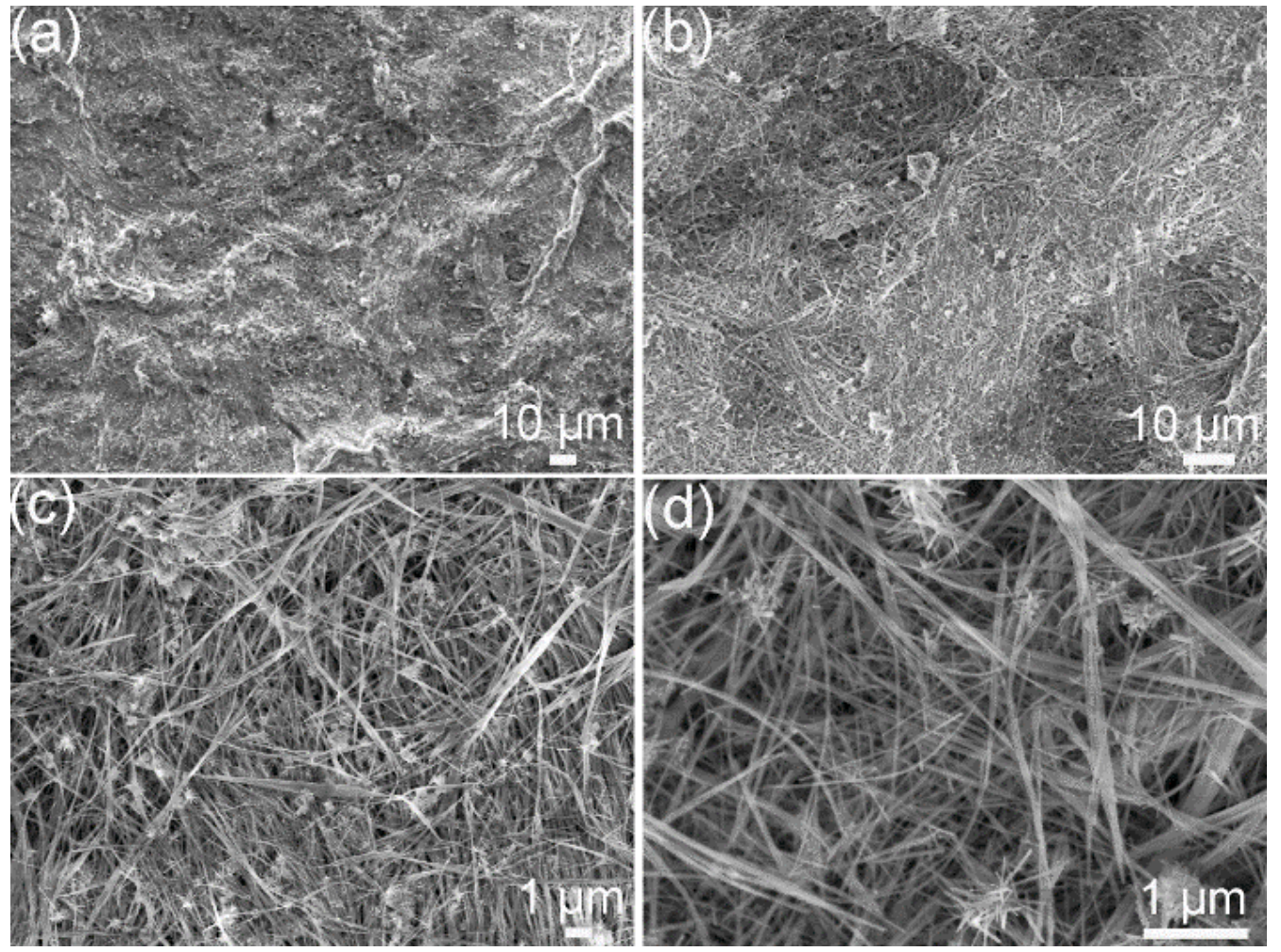

Figure 4. FE-SEM images of HA products synthesized by using $\mathrm{NaH}_{2} \mathrm{PO}_{4} \cdot 2 \mathrm{H}_{2} \mathrm{O}$ as the phosphate source at different magnifications. (a) $\times 500,(\mathbf{b}) \times 1000,(\mathbf{c}) \times 5000$ and $(\mathbf{d}) \times 20,000$.
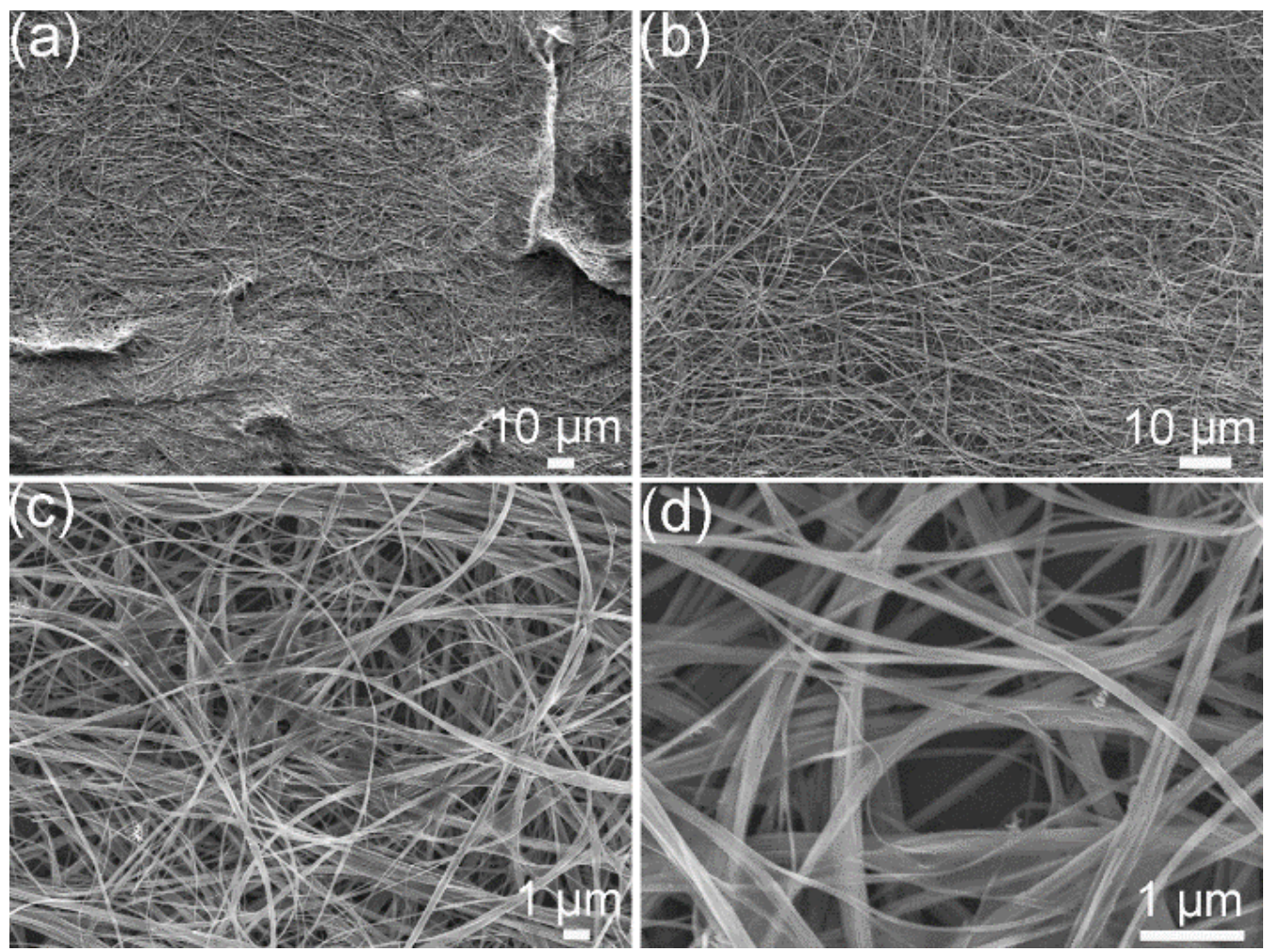

Figure 5. FE-SEM images of HA products synthesized by using $\mathrm{Na}_{3} \mathrm{PO}_{4} \cdot 12 \mathrm{H}_{2} \mathrm{O}$ as the phosphate source at different magnifications. (a) $\times 500,(\mathbf{b}) \times 1000,(\mathbf{c}) \times 5000$ and $(\mathbf{d}) \times 20,000$. 
From the above results, it is concluded that the morphology of synthesized HA gradually changes from agglomerated nanorods (Figure 3) to the coexistence of nanowires and flowerlike aggregates (Figure 4) and then to well-defined nanowires (Figure 5) under the control of different phosphates. The transition of such morphology confirms that phosphorus sources are crucial to the construction of HA nanomaterials.

\subsection{Formation Mechanism}

We proposed a possible formation mechanism to explain the morphological transformation of HA nanomaterials by using different phosphorus sources in solvothermal process. The chemical reactions of different phosphates in the reaction system are listed as follows:

$$
\begin{gathered}
6 \mathrm{PO}_{3}{ }^{-}+2 \mathrm{OH}^{-}+2 \mathrm{H}_{2} \mathrm{O} \rightarrow \mathrm{P}_{3} \mathrm{O}_{10}{ }^{5-}+3 \mathrm{H}_{2} \mathrm{PO}_{4}{ }^{-} \\
\mathrm{P}_{3} \mathrm{O}_{10}{ }^{5-}+4 \mathrm{OH}^{-} \rightarrow 3 \mathrm{PO}_{4}{ }^{3-}+2 \mathrm{H}_{2} \mathrm{O} \\
\mathrm{H}_{2} \mathrm{PO}_{4}{ }^{-}+2 \mathrm{OH}^{-} \rightarrow \mathrm{PO}_{4}{ }^{3-}+2 \mathrm{H}_{2} \mathrm{O}
\end{gathered}
$$

The phosphorus sources used in the reaction environment exist as the forms of $\mathrm{PO}_{3}{ }^{-}, \mathrm{H}_{2} \mathrm{PO}_{4}{ }^{-}$ and $\mathrm{PO}_{4}{ }^{3-}$ ions. As for $\mathrm{Na}_{3} \mathrm{PO}_{4} \cdot 12 \mathrm{H}_{2} \mathrm{O}$, it can release $\mathrm{PO}_{4}{ }^{3-}$ ions directly in the reaction solution to provide the phosphorus source necessary for the formation of HA. However, $\left(\mathrm{NaPO}_{3}\right)_{3}$ and $\mathrm{NaH}_{2} \mathrm{PO}_{4} \cdot 2 \mathrm{H}_{2} \mathrm{O}$ need to react with $\mathrm{NaOH}$ in the reaction solution according to chemical Equations (1)-(3) and Equation (3), respectively, and thus provide $\mathrm{PO}_{4}{ }^{3-}$ ions. These chemical reactions are not reversible. Accompanied by the steps, some of the phosphorus is consumed. The formation of HA nanorods may be explained by the above chemical reactions of $\left(\mathrm{NaPO}_{3}\right)_{3}$, and $\mathrm{NaH}_{2} \mathrm{PO}_{4} \cdot 2 \mathrm{H}_{2} \mathrm{O}$ to form $\mathrm{PO}_{4}{ }^{3-}$ ions which hinders the growth of $\mathrm{HA}$ along the $\mathrm{c}$ axis. Thus, the concentrations of $\mathrm{PO}_{4}{ }^{3-}$ and $\mathrm{OH}^{-}$ions in the reactions by using $\left(\mathrm{NaPO}_{3}\right)_{3}$ and $\mathrm{NaH}_{2} \mathrm{PO}_{4} \cdot 2 \mathrm{H}_{2} \mathrm{O}$ as the phosphates are lower than that of $\mathrm{Na}_{3} \mathrm{PO}_{4} \cdot 12 \mathrm{H}_{2} \mathrm{O}$. Meanwhile, the concentrations of $\mathrm{PO}_{4}{ }^{3-}$ and $\mathrm{OH}^{-}$ions in the reactions by using $\left(\mathrm{NaPO}_{3}\right)_{3}$ as a phosphate are the lowest, since it takes more steps to obtain $\mathrm{PO}_{4}{ }^{3-}$ ions. In this unique reaction system, oleic acid molecules can release $\mathrm{Ca}^{2+}$ sustainably to regulate the preferential growth of HA crystal. According to the above chemical reactions and literature [28], the hydrolysis rate of three phosphates can be compared as follows: $\mathrm{Na}_{3} \mathrm{PO}_{4} \cdot 12 \mathrm{H}_{2} \mathrm{O}>\mathrm{NaH}_{2} \mathrm{PO}_{4} \cdot 2 \mathrm{H}_{2} \mathrm{O}>\left(\mathrm{NaPO}_{3}\right)_{3}$.

As is illustrated in Figure 6, the nucleation points of HA crystals multiply with the increase of $\mathrm{PO}_{4}{ }^{3-}$ and $\mathrm{OH}^{-}$ions in the reaction environment. Figure $6 \mathrm{~A}$ shows the self-assembly process of HA aggregated nanorods by using $\left(\mathrm{NaPO}_{3}\right)_{3}$ as a phosphate. On one hand, a lower concentration of $\mathrm{PO}_{4}{ }^{3-}$ and $\mathrm{OH}^{-}$ions is beneficial to the formation of $\mathrm{HA}$ nanorods. On the other hand, the $\mathrm{P}_{3} \mathrm{O}_{10}{ }^{5-}$ ions generate by using $\left(\mathrm{NaPO}_{3}\right)_{3}$ as a phosphate chelate with $\mathrm{Ca}^{2+}$ in the reaction environment. The chelation hinders the growth of HA along the $\mathrm{c}$ axis, leading to the formation of HA nanorods. These newly formed nanorods are distributed freely at the bottom of the reactor. When the resultants are transferred to polar solvents, such as anhydrous ethanol, the alkyl chain molecules of oleic acid adsorbed on HA nanorods will make them self-assemble into regular arrangement patterns. The surface-induced instant self-assembly process is as follows. Oleic acid first adsorb on the surface of HA nanorods by the interaction between $\mathrm{Ca}^{2+}$ ions of $\mathrm{HA}$ and carboxylic groups of oleic acid. Then the constituents of oleic acid in the final product diffuse into anhydrous ethanol accompanied with the washing process. HA nanorods can be separated from the solution due to incompatibility between the alkyl chain molecules of oleic acid and anhydrous ethanol. During the solvent diffusion process, oleic acid adsorbed on the surface of HA nanorods can modulate the self-assembly process of regular arrangement patterns by the "anhydrous ethanol-oleic acid" interaction, expelling HA nanorods to form regular arrangement patterns. When $\mathrm{NaH}_{2} \mathrm{PO}_{4} \cdot 2 \mathrm{H}_{2} \mathrm{O}$ is used as the phosphorus source, the concentrations of $\mathrm{PO}_{4}{ }^{3-}$ and $\mathrm{OH}^{-}$ions in the reaction environment were higher than that with $\left(\mathrm{NaPO}_{3}\right)_{3}$ (Figure 6B). Therefore, the HA crystal nucleus was induced into short HA nanowires by oleic acid molecule. However, the concentrations of $\mathrm{PO}_{4}{ }^{3-}$ and $\mathrm{OH}^{-}$ions in the reaction environment still 
lead to the formation HA nanorods. When the resultants are transferred to polar solvents, the short HA nanowires self-assemble to grow HA long nanowires under the action of the oleic acid alkyl chain molecules attached to them, while the HA nanorods self-assemble into flowerlike aggregates. As for the reaction of $\mathrm{Na}_{3} \mathrm{PO}_{4} \cdot 12 \mathrm{H}_{2} \mathrm{O}$ as the phosphate, more $\mathrm{HA}$ nuclei occur due to the high concentrations of $\mathrm{PO}_{4}{ }^{3-}$ and $\mathrm{OH}^{-}$ions (Figure $6 \mathrm{C}$ ). Induced by oleic acid alkyl chain molecules, the HA nuclei grow rapidly into short HA nanowires as the reaction proceeded. Finally, ultralong HA nanowires with uniform morphology and good flexibility form when transferred to a polar solvent.

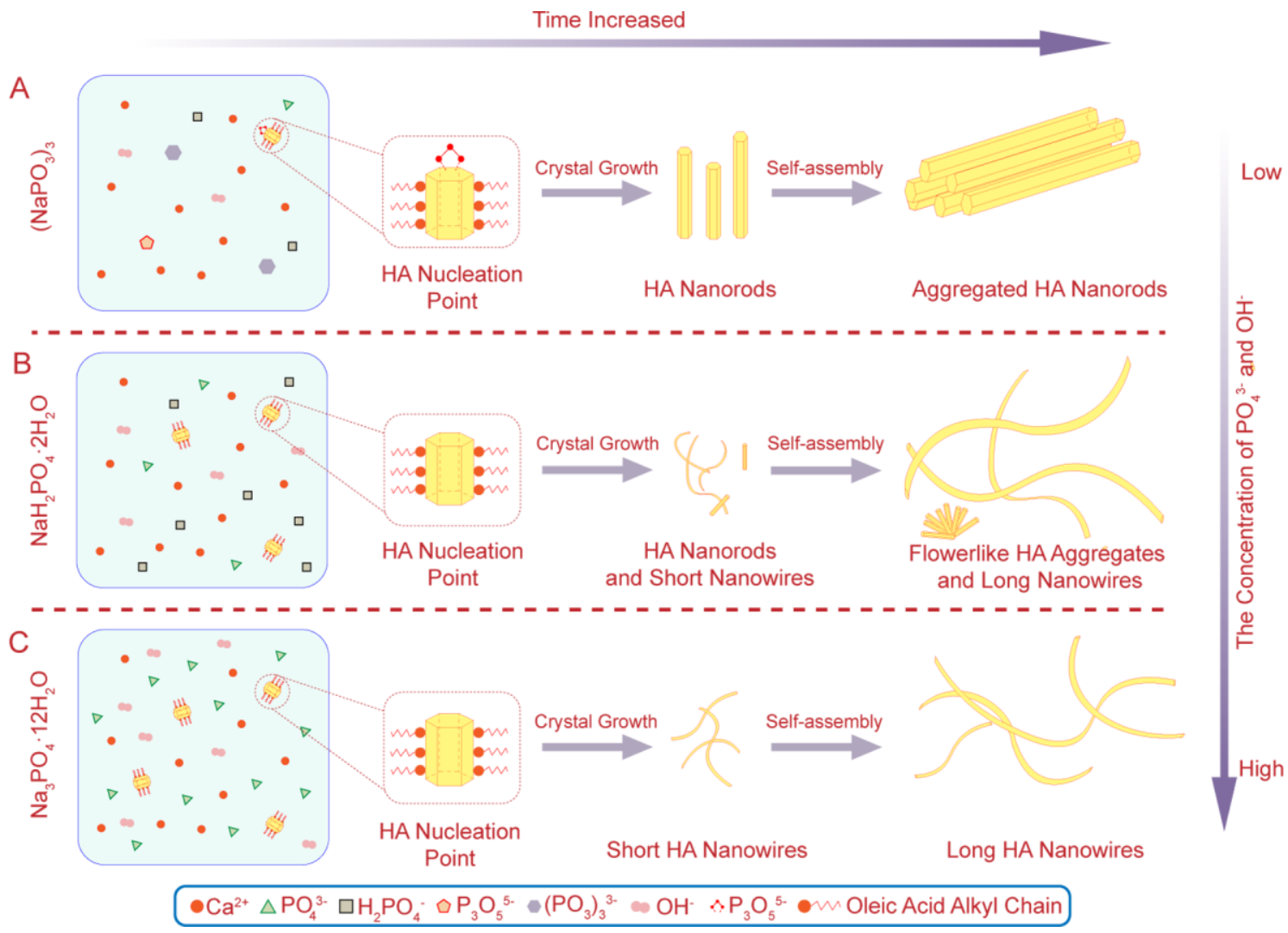

Figure 6. Formation mechanism of $\mathrm{HA}$ nanomaterials regulated by phosphorus sources under solvothermal conditions. (A) $\left(\mathrm{NaPO}_{3}\right)_{3},(\mathbf{B}) \mathrm{NaH}_{2} \mathrm{PO}_{4} \cdot 2 \mathrm{H}_{2} \mathrm{O}$ and (C) $\mathrm{Na}_{3} \mathrm{PO}_{4} \cdot 12 \mathrm{H}_{2} \mathrm{O}$.

\section{Conclusions}

HA nanomaterials with different morphologies are synthesized through a one-step solvothermal route by using $\left(\mathrm{NaPO}_{3}\right)_{3}, \mathrm{Na}_{3} \mathrm{PO}_{4} \cdot 12 \mathrm{H}_{2} \mathrm{O}$ and $\mathrm{NaH}_{2} \mathrm{PO}_{4} \cdot 2 \mathrm{H}_{2} \mathrm{O}$ as the phosphorus sources. The morphology of synthesized HA gradually changes from agglomerated nanorods to the coexistence of nanowires and flowerlike aggregates and then to well-defined nanowires under the control of different phosphates. The existence of phosphorus in the reactants leads to the morphology difference of HA nanomaterials. A possible formation mechanism of HA nanomaterials for the morphological transformation regulated by phosphates under solvothermal conditions is proposed. The strategy provides an instructive way to realize the controllable preparation of HA nanomaterials in the same reaction system and enlarge the biomedical applications of HA materials such as bone defect repair.

Author Contributions: Writing-original draft and writing-review \& editing, M.-1.Q.; investigation and methodology, S.Q.; software, Y.-c.W.; funding acquisition, S.Y.; resources, L.Q.; data curation, Y.W.; validation, Y.-p.L.; supervision, F.C. All authors have read and agreed to the published version of the manuscript.

Funding: This work was supported by the National Natural Science Foundation of China (11947117), China Postdoctoral Science Foundation (2019M660164) and the Doctoral Scientific Research Foundation of Shandong Jiaotong University (BS50004919). 
Acknowledgments: We would like to thank Materials Science and Engineering Laboratory of Shandong Jiaotong University for providing the experimental condition and the testing instruments.

Conflicts of Interest: The authors declare no conflict of interest. The funders had no role in the design of the study; in the collection, analyses, or interpretation of data; in the writing of the manuscript, or in the decision to publish the results.

\section{References}

1. Shojai, M.S.; Khorasani, M.T.; Khoshdargi, E.D.; Jamshidi, A. Synthesis methods for nanosized hydroxyapatite with diverse structures. Acta Biomater. 2013, 9, 7591-7621. [CrossRef]

2. Kanasan, N.; Adzila, S.; Koh, C.T.; Panerselvan, G. Effects of magnesium doping on the properties of hydroxyapatite/sodium alginate biocomposite. Adv. Appl. Ceram. 2019, 118, 381-386. [CrossRef]

3. Ratnayake, J.T.B.; Mucalo, R.; Dias, G.J. Substituted hydroxyapatites for bone regeneration: A review of current trends. J. Biomed. Mater. Res. B 2017, 105, 1285-1299. [CrossRef]

4. Zakaria, S.M.; Sharif, Z.; Othman, S.H.; Yang, M.R.; Jansen, F.J.A. Nanophase hydroxyapatite as a biomaterial in advanced hard tissue engineering: A review. Tissue Eng. Part B Rev. 2013, 19, 431-441. [CrossRef]

5. Sun, W.; Fan, J.; Wang, S.; Kang, Y.; Du, J.; Peng, X. Biodegradable drug-loaded hydroxyapatite nanotherapeutic agent for targeted drug release in tumors. ACS Appl. Mater. Inter. 2018, 10, 7832-7840. [CrossRef]

6. Shen, J.W.; Wu, T.; Wang, Q.; Pan, H.H. Molecular simulation of protein adsorption and desorption on hydroxyapatite surfaces. Biomaterials 2008, 29, 513-532. [CrossRef]

7. Phakatkar, A.H.; Shirdar, M.R.; Qi, M.; Taheri, M.M.; Narayanan, S.; Foroozan, T.; Sharifi-Asl, S.; Huang, Z.; Agrawal, M.; Lu, Y.; et al. Novel PMMA bone cement nanocomposites containing magnesium phosphate nanosheets and hydroxyapatite nanofibers. Mater. Sci. Eng. C 2020, 109, 110497. [CrossRef] [PubMed]

8. Alves Cardoso, D.; Jansen, J.A.; Leeuwenburgh, S.C. Synthesis and application of nanostructured calcium phosphate ceramics for bone regeneration. J. Biomed. Mater. Res. B Appl. Biomater. 2012, 100, 2316-2326. [CrossRef] [PubMed]

9. Wang, Y.-C.; Xu, W.-L.; Lu, Y.-P.; Xu, W.-H.; Yin, H.; Xiao, G.-Y. Investigation of nature of starting materials on the construction of hydroxyapatite 1D/3D morphologies. Mater. Sci. Eng. C 2020, 108, 110408. [CrossRef] [PubMed]

10. Cengiz, B.; Gokce, Y.; Yildiz, N.; Aktas, Z.; Calimli, A. Synthesis and characterization of hydroxyapatite nanoparticles. Colloids Surf. A 2008, 322, 29-33. [CrossRef]

11. Sun, F.; Zhou, H.J.; Lee, J. Various preparation methods of highly porous hydroxyapatite/polymer nanoscale biocomposites for bone regeneration. Acta Biomater. 2011, 7, 3813-3828. [CrossRef] [PubMed]

12. Lu, B.Q.; Zhu, Y.J.; Chen, F. Highly flexible and nonflammable inorganic hydroxyapatite paper. Chem. Eur. J. 2014, 20, 1242-1246. [CrossRef] [PubMed]

13. Jiang, Y.Y.; Zhu, Y.J.; Chen, F.; Wu, J. Solvothermal synthesis of submillimeter ultralong hydroxyapatite nanowires using a calcium oleate precursor in a series of monohydroxy alcohols. Ceram Int. 2015, 41, 6098-6102. [CrossRef]

14. Chen, F.F.; Zhu, Y.J.; Xiong, Z.C.; Dong, L.Y.; Chen, F.; Lu, B.Q.; Yang, R.L. Hydroxyapatite nanowire-based all-weather flexible electrically conductive paper with superhydrophobic and flame-retardant properties. ACS Appl. Mater. Inter. 2017, 9, 39534-39548. [CrossRef]

15. Sun, T.W.; Yu, W.L.; Zhu, Y.J.; Chen, F.; Zhang, Y.G.; Jiang, Y.Y.; He, Y.H. Porous nanocomposite comprising ultralong hydroxyapatite nanowires decorated with zinc-containing nanoparticles and chitosan: Synthesis and application in bone defect repair. Chemistry 2018, 24, 8809-8821. [CrossRef]

16. Zhao, X.Y.; Zhu, Y.J.; Chen, F.; Lu, B.Q.; Qi, C.; Zhao, J.; Wu, J. Hydrothermal synthesis of hydroxyapatite nanorods and nanowires using riboflavin- $5^{\prime}$-phosphate monosodium salt as a new phosphorus source and their application in proteinadsorption. Cryst. Eng. Comm. 2013, 15, 7926-7935. [CrossRef]

17. Chen, F.; Zhu, Y.J.; Wang, K.W.; Zhao, K.L. Surfactant-free solvothermal synthesis of hydroxyapatite nanowire/nanotube ordered arrays with biomimetic structures. Cryst. Eng. Comm. 2011, 13, 1858-1863. [CrossRef]

18. Cao, M.H.; Wang, Y.H.; Guo, C.X.; Qi, Y.J.; Hu, C.W. Preparation of ultrahigh-aspect-ratio hydroxyapatite nanofibers in reverse micelles under hydrothermal conditions. Langmuir 2004, 20, 4784-4786. [CrossRef] 
19. Yang, Z.; Huang, Y.; Chen, S.T.; Zhao, Y.Q.; Li, H.L. Template synthesis of highly ordered hydroxyapatite nanowire arrays. J. Mater. Sci. 2005, 40, 1121-1125. [CrossRef]

20. Costa, D.O.; Dixon, S.J.; Rizkalla, A.S. One- and Three-dimensional growth of hydroxyapatite nanowires during sol-gel-hydrothermal synthesis. ACS Appl. Mater. Inter. 2012, 4, 1490-1499. [CrossRef]

21. Reardon, P.J.T.; Handoko, A.D.; Li, L.; Huang, J.; Tang, J.W. Dimensionally and compositionally controlled growth of calcium phosphate nanowires for bone tissue regeneration. J. Mater. Chem. B 2013, 1, 6170-6176. [CrossRef] [PubMed]

22. Nakagawa, K.; Arai, Y.; Umezaki, Y.A.; Yoshida, Y.; Kajiwara, S.A.; Matsuyama, H.; Sugiyama, S. Template effect of phosphate surfactant on formation of hydroxyapatite nanostructures with various shapes. Mater. Chem. Phys. 2018, 213, 183-190. [CrossRef]

23. Zhang, Y.-G.; Zhu, Y.-J.; Chen, F.; Wu, J. Ultralong hydroxyapatite nanowires synthesized by solvothermal treatment using a series of phosphate sodium salts. Mater. Lett. 2015, 144, 135-137. [CrossRef]

24. Sun, R.X.; Chen, K.Z.; Liao, Z.M.; Meng, N. Controlled synthesis and thermal stability of hydroxyapatite hierarchical microstructures. Mater. Res. Bull. 2013, 48, 1143-1147. [CrossRef]

25. Qi, M.-L.; Qi, J.; Xiao, G.-Y.; Zhang, K.-Y.; Lu, C.-Y.; Lu, Y.-P. One-step hydrothermal synthesis of carbonated hydroxyapatite porous microspheres with a large and uniform size regulated by L-glutamic acid. Cryst. Eng. Comm. 2016, 18, 5876-5884. [CrossRef]

26. Lin, K.; Chang, J.; Zhu, Y.; Wu, W.; Cheng, G.; Zeng, Y.; Ruan, M. A facile one-step surfactant-free and low-temperature hydrothermal method to prepare uniform 3D structured carbonated apatite flowers. Cryst. Growth Des. 2008, 9, 177-181. [CrossRef]

27. Qi, M.-L.; Yao, S.; Liu, X.-C.; Wang, X.; Cui, F. Nanosheet-assembled carbonated hydroxyapatite microspheres prepared by an EDTA-assisted hydrothermal homogeneous precipitation route. Cryst. Eng. Comm. 2020, 22, 2884-2888. [CrossRef]

28. Li, H.; Zhu, Y.J.; Jiang, Y.Y.; Yu, Y.D.; Chen, F.; Dong, L.Y.; Wu, J. Hierarchical assembly of monodisperse hydroxyapatite nanowires and construction of high-strength fire-resistant inorganic paper with high-temperature flexibility. Chem. Nano. Mat. 2017, 3, 259-268. [CrossRef]

(C) 2020 by the authors. Licensee MDPI, Basel, Switzerland. This article is an open access article distributed under the terms and conditions of the Creative Commons Attribution (CC BY) license (http://creativecommons.org/licenses/by/4.0/). 